\title{
Early COPD patients with lung hyperinflation associated with poorer lung function but better bronchodilator responsiveness
}

This article was published in the following Dove Press journal:

International Journal of COPD

7 October 2016

Number of times this article has been viewed

\section{Chunlan Chen* \\ Wenhua Jian* \\ Yi Gao \\ Yanqing Xie \\ Yan Song \\ Jinping Zheng}

State Key Laboratory of Respiratory

Disease, China National Clinical

Research Center for Respiratory

Disease, Guangzhou Institute of

Respiratory Diseases, First Affiliated

Hospital of Guangzhou Medical

University, Guangzhou, People's

Republic of China

*These authors contributed equally to this work
Correspondence: Jinping Zheng State Key Laboratory of Respiratory

Disease, China National Clinical Research

Center for Respiratory Disease,

Guangzhou Institute of Respiratory

Diseases, First Affiliated Hospital of

Guangzhou Medical University, No I5I

Yanjiang Road, Guangzhou 5I0120,

People's Republic of China

Tel +86208306 2869

Fax +862083062729

Email jpzhenggy@।63.com
Background: It is unknown whether aggressive medication strategies should be used for early COPD with or without lung hyperinflation. We aimed to explore the characteristics and bronchodilator responsiveness of early COPD patients (stages I and II) with/without lung hyperinflation.

Methods: Four hundred and six patients with COPD who performed both lung volume and bronchodilation tests were retrospectively analyzed. Residual volume to total lung capacity $>120 \%$ of predicted values indicated lung hyperinflation. The characteristics and bronchodilator responsiveness were compared between the patients with and without lung hyperinflation across all stages of COPD.

Results: The percentages of patients with lung hyperinflation were $72.7 \%$ in the entire cohort, $19.4 \%$ in stage I, $68.5 \%$ in stage II, $95.3 \%$ in stage III, and $100.0 \%$ in stage IV. The patients with lung hyperinflation exhibited poorer lung function but better bronchodilator responsiveness of both forced expiratory volume in 1 second and forced vital capacity than those without lung hyperinflation during early COPD ( $t=2.21-5.70, P=0.000-0.029)$, especially in stage I, while age, body mass index, smoking status, smoking history, and disease duration were similar between the two subgroups in the same stages. From stages I to IV of subgroups with lung hyperinflation, stage I patients had the best bronchodilator responsiveness. Use of bronchodilator responsiveness of forced vital capacity to detect the presence of lung hyperinflation in COPD patients showed relatively high sensitivities $(69.5 \%-75.3 \%)$ and specificities $(70.3 \%-75.7 \%)$.

Conclusion: We demonstrated the novel finding that early COPD patients with lung hyperinflation are associated with poorer lung function but better bronchodilator responsiveness and established a simple method for detecting lung hyperinflation.

Keywords: GOLD I, GOLD II, RV/TLC, bronchodilation test

\section{Introduction}

COPD is a global disease with increasing morbidity, disability, and burden. ${ }^{1,2}$ A notable characteristic of COPD is the persistent airflow limitation, which usually develops progressively. ${ }^{1}$ The annual rates of decline in forced expiratory volume in 1 second $\left(\mathrm{FEV}_{1}\right)$ in patients with early COPD (stages I and II) are more rapid than those in patients with stages III and IV COPD. ${ }^{3-5}$ For early stable COPD, the Global initiative for chronic Obstructive Lung Disease (GOLD) recommends regular and aggressive pharmacological treatment only for patients with high level of symptoms. ${ }^{1}$ However, drug interventions during early COPD that depend on subjective symptoms may not be sufficient, while most patients do not visit hospitals or clinics until they have developed 
more severe degree of COPD by the time the diagnosis is made. ${ }^{6}$ To achieve early COPD intervention, especially during GOLD stage I, objective "markers" for aggressive medication strategies should be taken into account.

In a previous study, the indices of lung hyperinflation increased exponentially across GOLD stages, ${ }^{7}$ resulting in increased dyspnea and limitation of exercise capacity for patients with COPD. ${ }^{8,9}$ Moreover, static hyperinflation is an independent predictor of frequent exacerbations ${ }^{10}$ and even mortality in patients with COPD. ${ }^{11,12}$ Patients with greater resting lung hyperinflation showed more bronchodilatorinduced volume deflation effects. ${ }^{7}$ Given the earlier associations, considerable interest exists in evaluating the clinical utility of lung hyperinflation as objective "marker" in COPD. However, it is unknown whether aggressive medication strategies should be used during early COPD (particularly for GOLD stage I) with or without lung hyperinflation. In addition, when considering COPD management in primary care settings, simple methods that do not use advanced equipment and complex technology to detect lung hyperinflation should be established.

Therefore, the purposes of the present study were a) to explore the characteristics and bronchodilator responsiveness of early COPD patients with or without lung hyperinflation and b) to test the feasibility of using bronchodilator responsiveness to detect lung hyperinflation in patients with early COPD.

\section{Methods}

\section{Patients}

This retrospective study included 406 stable patients with COPD first diagnosed by pulmonary physicians using GOLD definition in the First Affiliated Hospital of Guangzhou Medical University from January 2011 to June 2015. COPD patients were aged $\geq 40$ years, had been evaluated by using both lung volume and bronchodilation tests, and had postbronchodilator $\mathrm{FEV}_{1}$ /forced vital capacity (FVC) values $<0.70$. Patients were excluded if they had experienced a respiratory infection or an exacerbation of COPD within the last 4 weeks, had a history of pulmonary resection or asthma, used supplemental oxygen for $>12$ hours per day, or had significant diseases other than COPD that might influence either the results of the study or the patient's ability to perform tests. The stages of COPD conformed to GOLD guidelines: GOLD stage I, predicted $\mathrm{FEV}_{1}$ value ( $\mathrm{FEV}_{1} \%$ pred) $\geq 80 \%$; GOLD stage II, $50 \% \leq \mathrm{FEV}_{1} \%$ pred $<80 \%$; GOLD stage III, $30 \% \leq \mathrm{FEV}_{1} \%$ pred $<50 \%$; and GOLD stage IV, FEV $_{1} \%$ pred $<30 \% .{ }^{1}$
Written informed consent of pulmonary function test (PFT) was obtained from all patients prior to the test, and the study protocol was approved by the First Affiliated Hospital of Guangzhou Medical University Ethics Committee. All patient information was kept confidential.

\section{Pulmonary function test}

The PFT equipment (Jaeger Masterscreen Body, BD, Franklin Lakes, NJ, USA; Cosmed PFT Quark, COSMED, The Metabolic Company, Rome, Italy) met the criteria of the American Thoracic Society and the European Respiratory Society. ${ }^{13,14}$ Calibration checks were performed daily prior to all tests and validated that the devices were within the calibration limits. Patients were required to refrain from the use of short- and long-acting bronchodilators (for $\geq 6$ and $\geq 24$ hours, respectively), short- and long-acting theophylline (for $\geq 24$ and $\geq 48$ hours, respectively), antileukotrienes (for $\geq 48$ hours), smoking, exercise, and tea/coffee (for $\geq 4$ hours).

All lung volume and bronchodilation tests were conducted by skilled and certified doctors/technicians according to American Thoracic Society and the European Respiratory Society guidelines. ${ }^{13-15}$ For the lung volume test, body plethysmography or multiple-breath $\mathrm{N}_{2}$ washout was performed. Then, spirometry was performed before and 20-30 minutes after administration of $400 \mu \mathrm{g}$ of salbutamol via metered dose inhaler. The change in $\mathrm{FEV}_{1}$ was expressed as 1) the percentage change relative to baseline ( $\triangle \mathrm{FEV}_{1} \%$ baseline $), 2$ ) the absolute change in the percentage of the predicted value $\left(\triangle \mathrm{FEV}_{1} \%\right.$ pred), and 3$)$ the absolute change relative to baseline $\left(\Delta \mathrm{FEV}_{1}\right)$. The change in $\mathrm{FVC}$ was expressed in a similar manner. Predicted values of lung volume and spirometry were calculated from the reference equations published by Stocks et $\mathrm{a}^{16}$ and Zheng and Zhong, ${ }^{17}$ respectively. An abnormal ratio of residual volume to total lung capacity (RV/TLC) was considered pathological. RV/TLC values $>120 \%$ of predicted values indicated lung hyperinflation.

\section{Statistical analysis}

Data were analyzed by using SPSS 18.0 software (SPSS Inc., Chicago, IL, USA). The characteristics of the study population are reported as mean \pm standard deviation or as counts and percentages unless otherwise specified. Group differences between the presence and absence of lung hyperinflation within the entire cohort and each GOLD stage were explored using an unpaired $t$-test, a Mann-Whitney $U$-test, or a $\chi^{2}$-square test where appropriate. Comparisons across GOLD stages were analyzed using analysis of variance. 
Pearson's correlation was used to evaluate the relationships between the $\mathrm{RV} / \mathrm{TLC} \%$ pred and bronchodilator responsiveness of the $\mathrm{FVC}$ and $\mathrm{FEV}_{1}$. Multivariate logistic regression analyses with age, sex, body mass index (BMI), technology of lung volume test, smoking status, self-reported smoking history, self-reported COPD duration, GOLD stage, $\triangle \mathrm{FVC}$, and $\triangle \mathrm{FEV}_{1}$ were used to determine the association between these characteristics and the presence or absence of lung hyperinflation. Receiver operating characteristic curves were generated for selected cutoff values of bronchodilator responsiveness to detect lung hyperinflation. $P$-values $<0.05$ were considered significant in all analyses.

\section{Results}

\section{Population characteristics}

Of the 406 patients in the present study, 369 (90.9\%) were males and 37 (9.1\%) were females. The distribution of COPD stages was $16.5 \%$ in GOLD stage I, 39.9\% in GOLD stage II, $31.3 \%$ in GOLD stage III, and $12.3 \%$ in GOLD stage IV (Table 1). The mean age, sex, and smoking status were similar within each GOLD stage subgroup, while greater self-reported smoking history (pack-year); longer selfreported COPD duration; higher RV\%pred, TLC\%pred, and RV/TLC\%pred; and lower BMI, FVC\%pred, FEV \% $\%$ pred, and $\mathrm{FEV}_{1} / \mathrm{FVC}^{\circ}$ were showed in the greater severity subgroup $(F=2.89-972.11, P=0.000-0.035)$.

\section{Characteristics and bronchodilator responsiveness of patients with or without lung hyperinflation}

The percentages of patients with lung hyperinflation were $72.7 \%$ in the entire cohort, $19.4 \%$ in GOLD stage I, $68.5 \%$ in stage II, $95.3 \%$ in stage III, and $100.0 \%$ in stage IV (Table 1). Although patients with lung hyperinflation had lower BMIs and reported a greater smoking history and longer disease duration than those without lung hyperinflation in the entire cohort $(|t|=2.02-4.30, P=0.000-0.044)$, no significant differences were found in terms of mean age, sex, BMI, smoking status, smoking history, and disease duration between patients with and without lung hyperinflation in GOLD stages I and II. Nevertheless, patients with lung hyperinflation had lower $\mathrm{FVC} \%$ pred and $\mathrm{FEV}_{1} \%$ pred and higher RV\%pred, TLC\%pred, and RV/TLC\%pred values than those without lung hyperinflation in GOLD stages I and II $(|t|=2.54-17.28, P=0.000-0.013)$.

Regarding the bronchodilator responsiveness of the entire cohort (Table 2), patients with lung hyperinflation showed significant improvement in FVC compared to those without hyperinflation $(0.27 \pm 0.21 \mathrm{~L}$ vs $0.09 \pm 0.15 \mathrm{~L}$, $t=9.88, P<0.001)$, but no significant improvement in $\mathrm{FEV}_{1}$ $(0.14 \pm 0.12 \mathrm{~L}$ vs $0.13 \pm 0.10 \mathrm{~L}, t=1.28, P=0.201)$. However, the improvements of both $\mathrm{FVC}$ and $\mathrm{FEV}_{1}$ in patients with lung hyperinflation were significantly higher than those in patients without lung hyperinflation in GOLD stages I $(0.32 \pm 0.20 \mathrm{~L}$ vs $0.08 \pm 0.15 \mathrm{~L}, t=4.83, P<0.001 ; 0.30 \pm 0.18 \mathrm{~L}$ vs $0.13 \pm 0.11 \mathrm{~L}$, $t=3.15, P=0.007$, respectively) and II $(0.26 \pm 0.22 \mathrm{~L}$ vs $0.09 \pm 0.15 \mathrm{~L}, t=5.70, P<0.001 ; 0.17 \pm 0.11 \mathrm{~L}$ vs $0.13 \pm 0.10 \mathrm{~L}$, $t=2.21, P=0.029$, respectively). Among the patients with lung hyperinflation across each COPD stage, subgroup differences existed for $\mathrm{FEV}_{1}$ improvement $(F=19.72, P<0.001)$, but not for FVC improvement ( $F=0.85, P=0.469)$. In addition, the present study showed no difference in the poor bronchodilator responsiveness between GOLD stages I and II without lung hyperinflation $(|t|=0.08-1.56, P=0.121-0.940)$.

\section{Logistic regression for patients with lung hyperinflation}

The variables from the multivariate logistic regression model are listed in Table 3. The odds for meeting lung hyperinflation criteria tended to be higher for females than males. The model also showed that higher odds of lung hyperinflation were associated with increased COPD severity. The $\triangle \mathrm{FVC}$ was the most significant factor, and patients with greater $\triangle \mathrm{FVC}$ tended to exhibit higher odds of lung hyperinflation. However, age, BMI, technology of lung volume test, smoking status, smoking history, disease duration, and $\triangle \mathrm{FEV}_{1}$ were not significant in the logistic regression analysis.

\section{Cutoff values of bronchodilator responsiveness used to detect lung hyperinflation}

Linear relationships were observed between $\mathrm{RV} / \mathrm{TLC} \%$ pred and $\Delta \mathrm{FVC}(r=0.386, P<0.001), \Delta \mathrm{FVC} \%$ baseline $(r=0.495$, $P<0.001)$, and $\Delta \mathrm{FVC} \% \operatorname{pred}(r=0.378, P<0.001)$ (Figure 1$)$. The relationships between $\mathrm{RV} / \mathrm{TLC} \%$ pred and $\triangle \mathrm{FEV}_{1}$ $(r=-0.002, P=0.975)$ and $\Delta \mathrm{FEV}_{1} \%$ pred $(r=-0.012, P=806)$ were poor, except for $\mathrm{RV} / \mathrm{TLC} \%$ pred and $\triangle \mathrm{FEV}_{1} \%$ baseline $(r=0.362, P<0.001)$.

The area under the receiver operating characteristic curve (AUC) for the entire cohort for detecting lung hyperinflation with $\triangle \mathrm{FVC} \%$ baseline was highest (0.811), followed by $\triangle \mathrm{FVC}$ and $\triangle \mathrm{FVC} \%$ pred, with AUCs of 0.766 and 0.767 , respectively (Figure 2). In addition, the AUCs of the GOLD stages I-III were $0.838,0.774$, and 0.756 , respectively, when using $\triangle \mathrm{FVC} \%$ baseline to predict lung hyperinflation, indicating that earlier stages exhibited larger AUCs. 


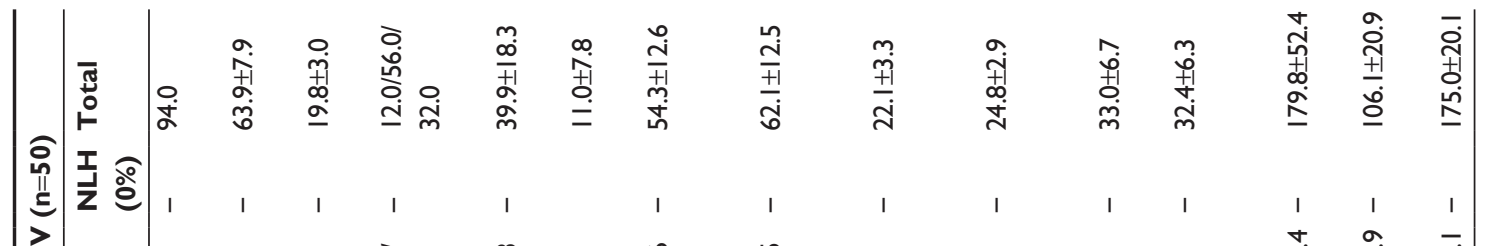

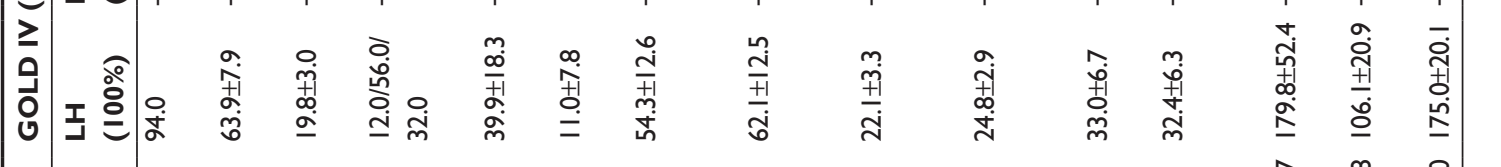

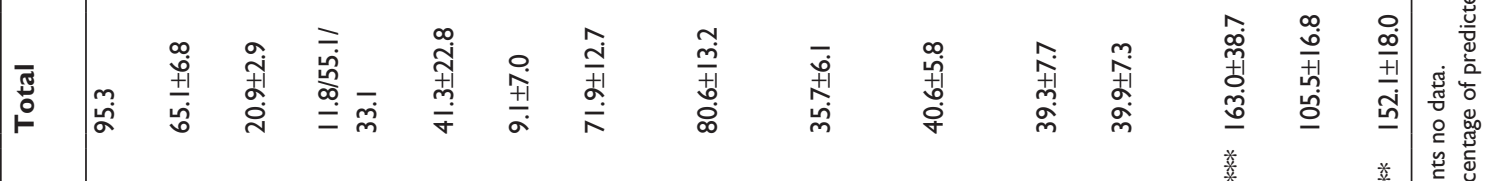

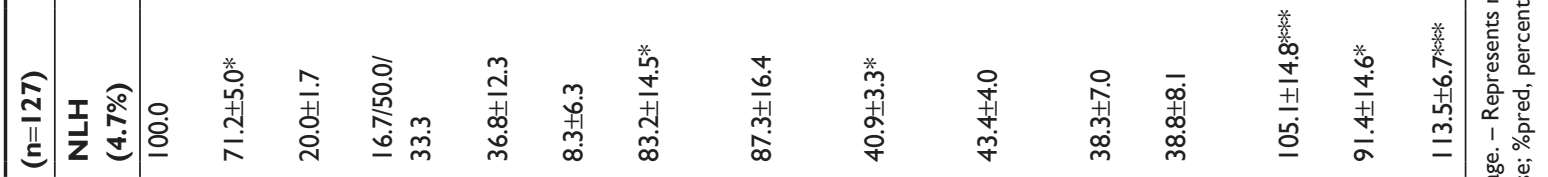

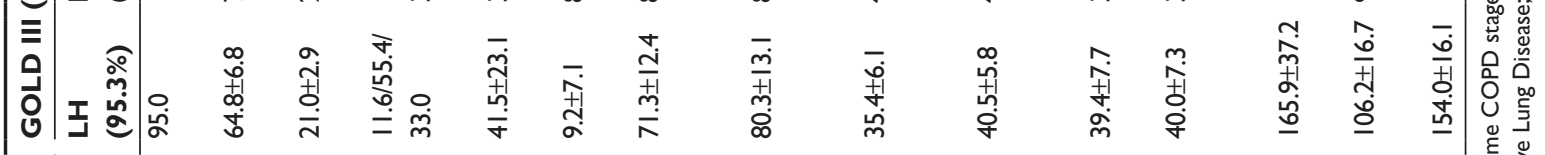

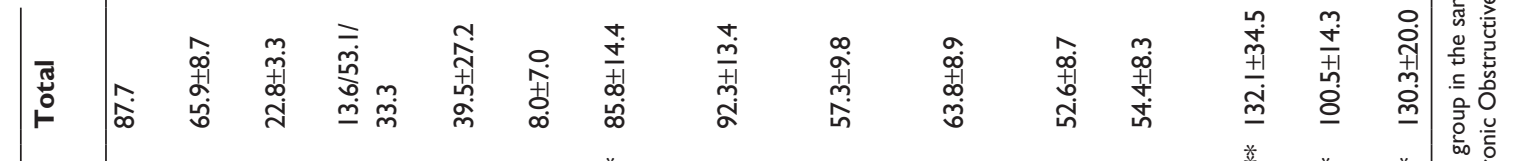

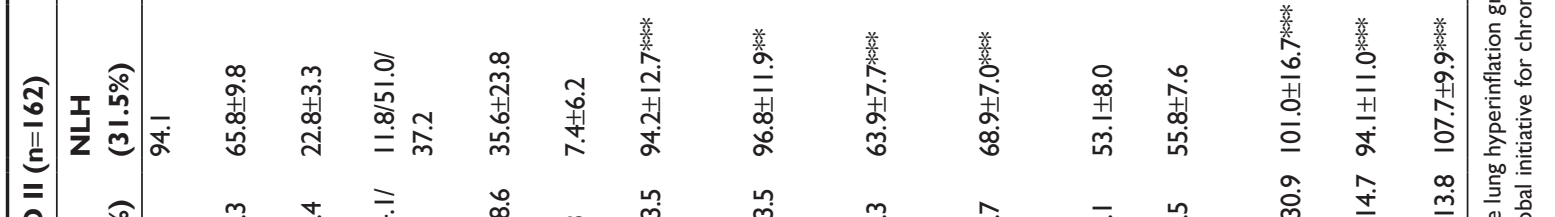

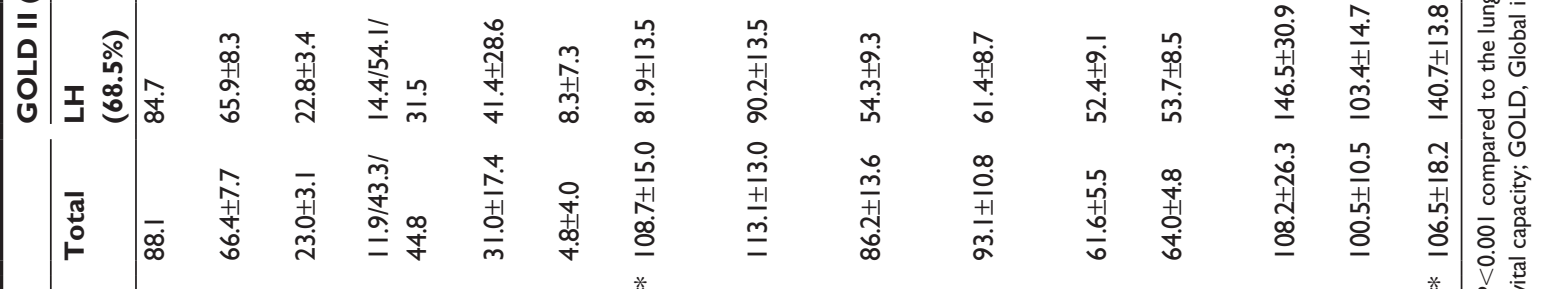

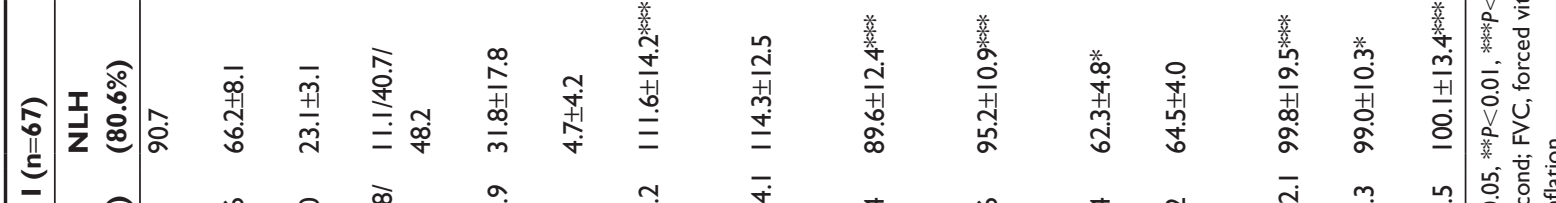

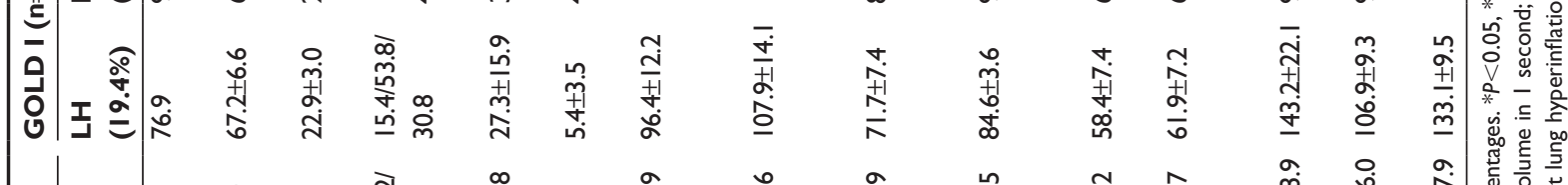

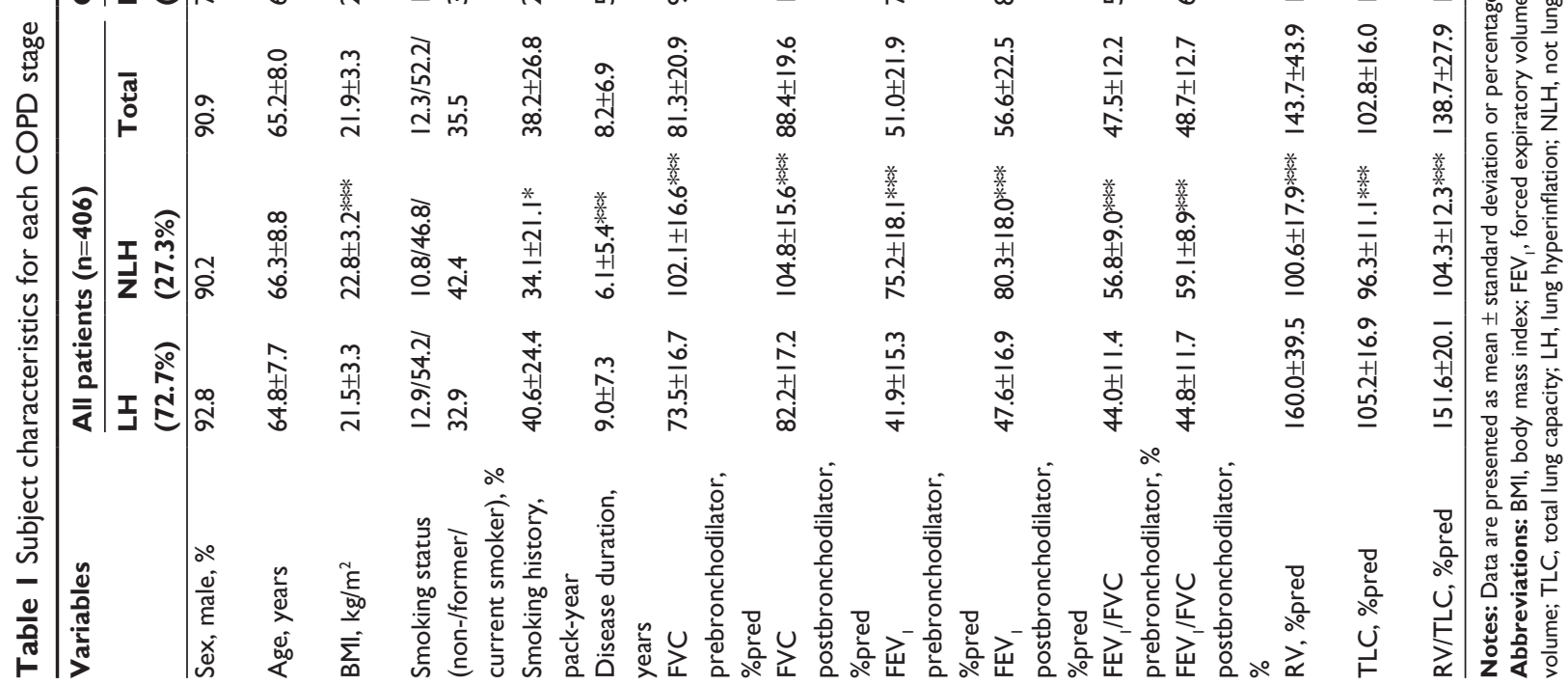




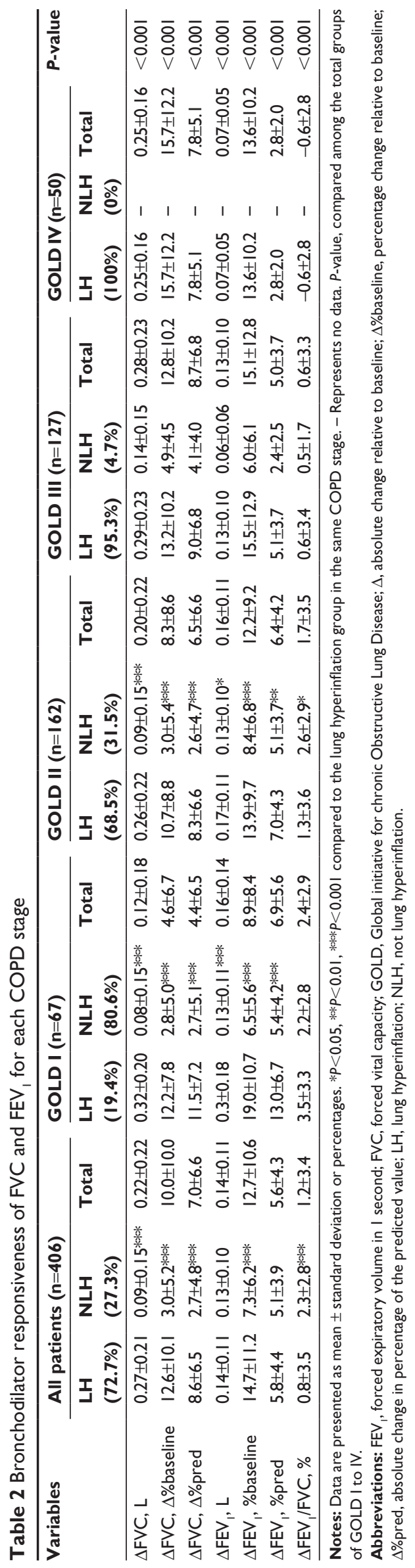

The cutoff values with the best sensitivity and specificity for each functional variable were selected according to the receiver operating characteristic analysis: $0.15 \mathrm{~L}$ of $\Delta \mathrm{FVC}$ with a sensitivity of $70.2 \%$ and a specificity of $71.2 \%, 6.0 \%$ of $\triangle \mathrm{FVC} \%$ baseline with a sensitivity of $75.3 \%$ and a specificity of $75.7 \%$, and $5.0 \%$ of $\Delta \mathrm{FVC} \%$ pred with a sensitivity of $69.5 \%$ and a specificity of $70.3 \%$.

\section{Discussion}

The main findings of the present study were as follows: 1) early COPD patients with lung hyperinflation showed poorer lung function but better bronchodilator responsiveness than those without lung hyperinflation, especially in GOLD stage I, while age, BMI, smoking status, smoking history, and disease duration were similar between the two subgroups for the same COPD stages; 2) the bronchodilator responsiveness of FVC was similar in patients with lung hyperinflation across COPD stages, while greater bronchodilator responsiveness of $\mathrm{FEV}_{1}$ was detected in earlier COPD patients with lung hyperinflation; and 3) use of bronchodilator responsiveness of FVC to detect the presence of lung hyperinflation in early COPD is a simple method with relatively high sensitivity and specificity.

Up to $72.7 \%$ of patients exhibited lung hyperinflation in the entire study cohort, while the rate increased with the stage of COPD. Unlike previous studies that focused on the bronchodilator responsiveness and treatment effect in each stage of COPD as a whole, ${ }^{7,18,19}$ the present study provided a novel analysis of the two subgroups within each COPD stage (patients with/without lung hyperinflation) in terms of characteristics, lung function, and bronchodilator responsiveness. The study of Ortega et $\mathrm{al}^{20}$ reported that better bronchodilator responsiveness was associated with poorer quality of life and exercise capacity in patients with severe COPD. Our study found that early COPD patients with lung hyperinflation were associated with poorer lung function but better bronchodilator responsiveness (Tables 1 and 2). Hence, we hypothesized that poorer lung function but better bronchodilator responsiveness might associate with poorer quality of life and exercise capacity. In addition, the present study showed no difference in the poor bronchodilator responsiveness between GOLD stages I and II without lung hyperinflation. Therefore, the presence of lung hyperinflation may serve as an objective "marker" for aggressive pharmacological intervention for early COPD, especially for GOLD stage I, which complements subjective assessments.

Within the patient population, some characteristics and bronchodilator responsiveness appeared to be associated with the presence of lung hyperinflation in the multivariate logistic regression. Females appeared to exhibit lung hyperinflation 
Table 3 Multivariate logistic regression analysis of patients with lung hyperinflation

\begin{tabular}{|c|c|c|}
\hline Variables & OR $(95 \% \mathrm{CI})$ & $P$-value \\
\hline Sex & $0.207(0.067-0.636)$ & 0.006 \\
\hline Age & $0.996(0.955-1.038)$ & 0.844 \\
\hline BMI & $0.958(0.865-1.061)$ & 0.411 \\
\hline Technology of lung volume test & $1.206(0.58 \mathrm{I}-2.503)$ & 0.616 \\
\hline Smoking status & $0.957(0.553-1.655)$ & 0.874 \\
\hline Smoking history & $1.006(0.992-1.019)$ & 0.409 \\
\hline Disease duration & $1.052(0.999-I .106)$ & 0.052 \\
\hline GOLD stage & $9.852(5.368-18.082)$ & $<0.001$ \\
\hline$\Delta \mathrm{FVC}$ & | $44.836(|7.755-|,|8| .484)$ & $<0.001$ \\
\hline$\Delta \mathrm{FEV}_{\mathrm{I}}$ & $7.840(0.227-270.436)$ & 0.254 \\
\hline
\end{tabular}

Abbreviations: $\mathrm{BMI}$, body mass index; $\mathrm{Cl}$, confidence interval; $\mathrm{FEV}_{1}$, forced expiratory volume in I second; FVC, forced vital capacity; GOLD, Global initiative for chronic Obstructive Lung Disease; OR, odds ratio; $\Delta$, absolute change relative to baseline.

more often than males, but this observation should be viewed with caution given the limited sample size of female patients. Patients without lung hyperinflation generally exhibited milder COPD, and the indices that were not associated with lung hyperinflation, such as BMI, smoking history, and disease duration, could be explained based on the COPD stage. Moreover, the $\triangle \mathrm{FVC}$ was the most significant factor associated with lung hyperinflation. In addition, we also found a positive correlation between FVC improvement and the RV/ TLC\%pred. Therefore, it is possible to use the bronchodilator responsiveness of FVC to detect high $\mathrm{RV} / \mathrm{TLC} \%$ pred (lung hyperinflation).

Except for lung volume tests, recent evidence has supported using radiography methods, such as computed tomography, to evaluate lung hyperinflation severity in patients with COPD. ${ }^{21-23}$ These assessments are intuitive and accurate, but the radiographic method is not a repeatable or acceptable choice due to its high cost and level of radiation exposure. Considering the lack of advanced equipment and complex technology in primary care settings, especially in developing countries, the present study provided a simple method to detect lung hyperinflation, in which the cutoff values of $\triangle \mathrm{FVC}$ and its derivatives exhibited relatively high sensitivity and specificity, especially for GOLD stage I patients. Although the shortcoming of the cutoff value of FVC change is somewhat similar to that of the reversibility of $\mathrm{FEV}_{1}{ }_{1}{ }^{24}$ this simple method still could use for screening lung hyperinflation in a COPD population. In addition, the same meaning as FVC, increase of inspiratory capacity after bronchodilator inhalation suggests a reduction of dynamic hyperinflation. However, FVC could be obtained simultaneously when spirometry maneuver was performed; by comparison, inspiratory capacity has to be tested separately. Moreover, the reliability and quality control of inspiratory capacity are poor in some instances. Therefore, FVC has the advantage of easier obtainment in the clinical practice.
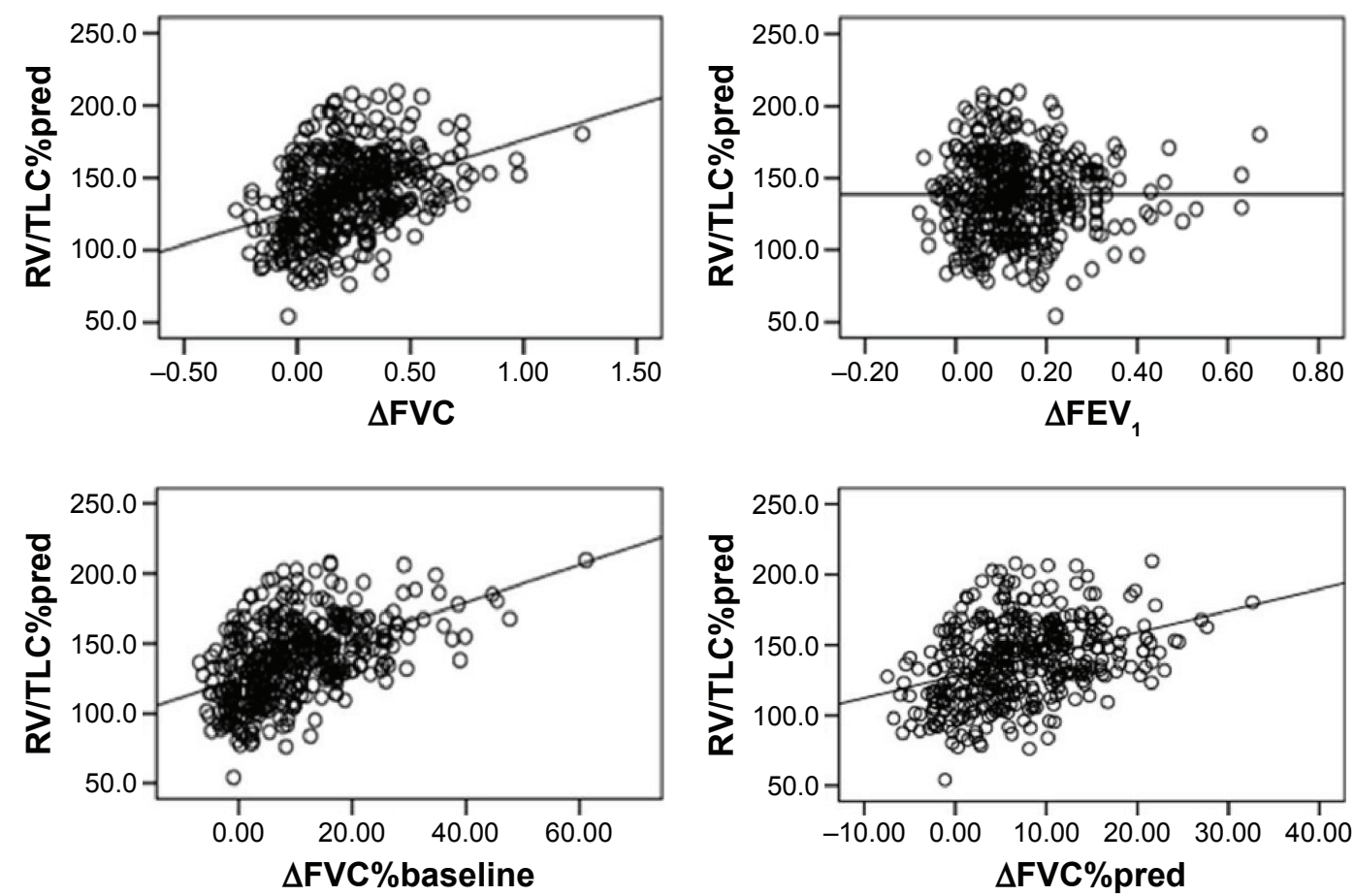

Figure I Scatter diagrams for RV/TLC\%pred versus $\Delta \mathrm{FVC}, \Delta \mathrm{FVC} \%$ baseline, $\Delta \mathrm{FVC} \%$ pred, and $\Delta \mathrm{FEV}$.

Abbreviations: $\mathrm{FEV}$, forced expiratory volume in I second; FVC, forced vital capacity; RV, residual volume; TLC, total lung capacity; \%pred, percentage of predicted value; $\Delta$, absolute change relative to baseline; $\Delta \%$ baseline, percentage change relative to baseline. 

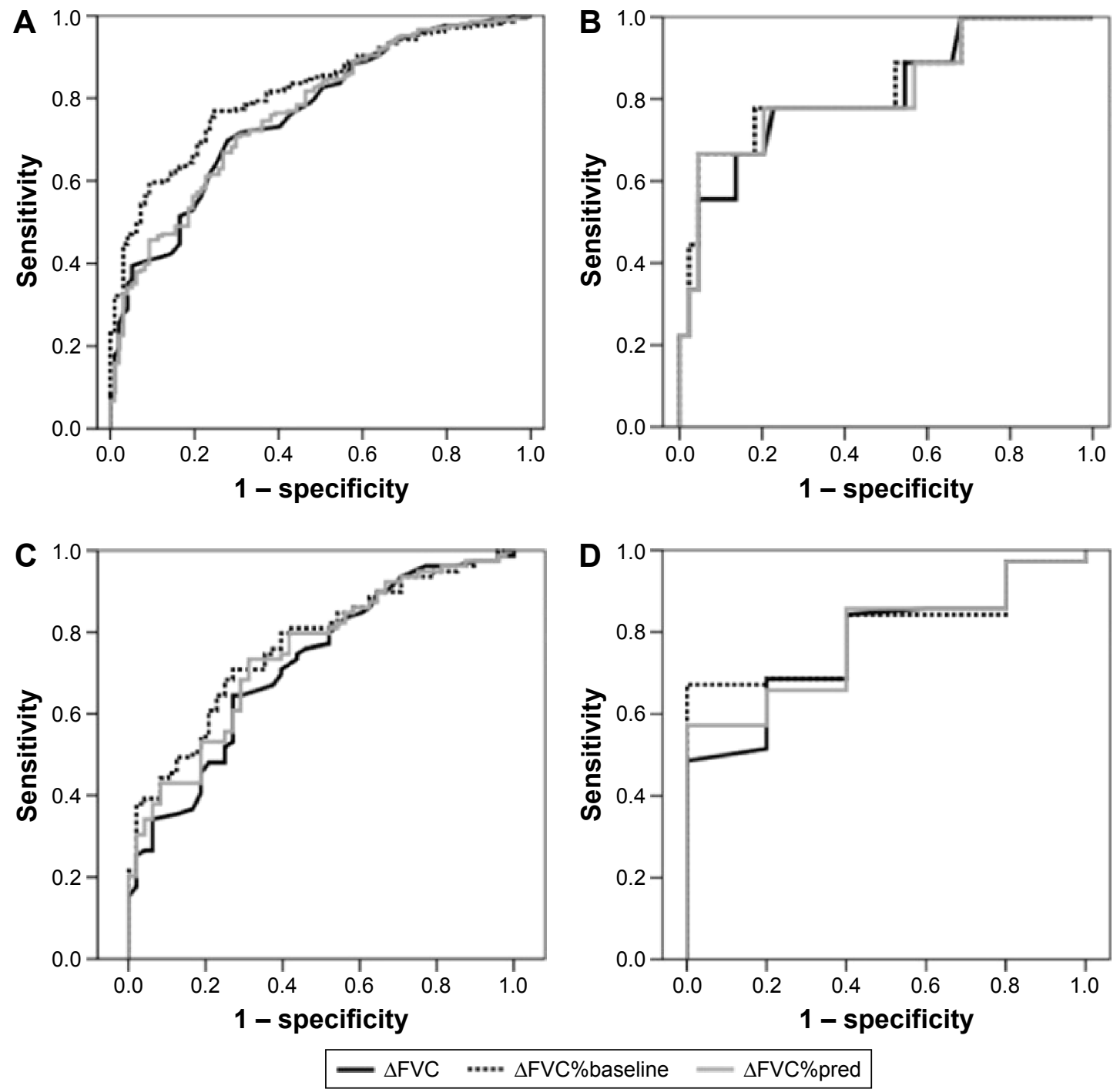

Figure 2 Receiver operating characteristic curves for detecting lung hyperinflation in patients with COPD.

Notes: (A) The entire cohort, (B) COPD stage I, (C) COPD stage II, and (D) COPD stage III.

Abbreviations: FVC, forced vital capacity; $\Delta$, absolute change relative to baseline; $\Delta \%$ baseline, percentage change relative to baseline; $\Delta \%$ pred, absolute change in percentage of the predicted value.

\section{Limitations}

Some limitations were present in our study. As a retrospective study, we could not record additional clinical data from the COPD patients, such as modified medical research council scores, COPD assessment test scores, and the number of exacerbation events during the previous year. The multiplebreath $\mathrm{N}_{2}$ washout was performed in $78.6 \%$ of patients, while the lung volume measured by body plethysmography differs with that measured by multiple-breath $\mathrm{N}_{2}$ washout in COPD, the more, the higher grade of obstruction..$^{14}$ However, the present study focused on early COPD that with lower grade of obstruction, and the technology of lung volume test did not show any significance in the logistic regression analysis for detecting lung hyperinflation. In addition, the number of patients with GOLD stage I and female patients was relatively small, although they did reflect the reality of COPD management in the People's Republic of China. ${ }^{25}$ Nevertheless, we found evidence that lung hyperinflation in patients with early COPD is associated with poorer lung function but better bronchodilator responsiveness. These limitations have been considered in our upcoming study, which prospectively focuses on the long-term treatment effects and clinical outcomes of patients with or without lung hyperinflation in early COPD, especially in GOLD stage I.

\section{Conclusion}

This study provided novel findings regarding the presence of lung hyperinflation in COPD patients, which may serve 
as an objective "marker" for aggressive pharmacological intervention for early COPD. In addition, the present study established a simple method using the bronchodilator responsiveness of FVC to detect lung hyperinflation.

\section{Acknowledgments}

This work was supported by chronic respiratory diseases funding, Chinese Medical Association research projects, National Key Technology R\&D Program, and Natural Science Foundation for Young of China (2012BAI05B01, 2013BAI09B09, 2014Y2-00540, 2015BAI12B10, 81300017).

\section{Author contributions}

$\mathrm{JZ}$ is the guarantor of the paper, had full access to all the data in the study, and takes responsibility for the integrity of the data and the accuracy of the data analysis. WJ contributed to study design, quality control, acquisition of the data, statistical analysis, and revising of the manuscript. CC contributed to quality control, acquisition of the data, statistical analysis, and drafting of the manuscript. All authors contributed toward data analysis, drafting and revising the paper and agree to be accountable for all aspects of the work. All the authors have read and approved the final manuscript.

\section{Disclosure}

The authors report no conflicts of interest in this work.

\section{References}

1. Vestbo J, Hurd SS, Agustí AG, et al. Global strategy for the diagnosis, management, and prevention of chronic obstructive pulmonary disease: gold executive summary. Am J Respir Crit Care Med. 2013;187(4): 347-365.

2. Buist AS, Vollmer WM, McBurnie MA. Worldwide burden of COPD in high- and low-income countries. Part I. The burden of obstructive lung disease (BOLD) initiative. Int J Tuberc Lung Dis. 2008;12(7):703-708.

3. The Lung Health Study Research Group. Effect of inhaled triamcinolone on the decline in pulmonary function in chronic obstructive pulmonary disease. N Engl J Med. 2000;343(26):1902-1909.

4. Tashkin DP, Celli B, Senn S, et al; UPLIFT Study Investigators. A 4-year trial of tiotropium in chronic obstructive pulmonary disease. $N$ Engl $J$ Med. 2008;359(15):1543-1554.

5. Decramer M, Celli B, Kesten S, Mehra S, Tashkin DP; UPLIFT investigators. Effect of tiotropium on outcomes in patients with moderate chronic obstructive pulmonary disease (UPLIFT): a prespecified subgroup analysis of a randomized controlled trial. Lancet. 2009;374(9696):1171-1178.

International Journal of COPD

\section{Publish your work in this journal}

The International Journal of COPD is an international, peer-reviewed journal of therapeutics and pharmacology focusing on concise rapid reporting of clinical studies and reviews in COPD. Special focus is given to the pathophysiological processes underlying the disease, intervention programs, patient focused education, and self management protocols.
6. Price D, Freeman D, Cleland J, Kaplan A, Cerasoli F. Earlier diagnosis and earlier treatment of COPD in primary care. Prim Care Respir J. 2011; 20(1):15-22.

7. Deesomchok A, Webb KA, Forkert L, et al. Lung hyperinflation and its reversibility in patients with airway obstruction of varying severity. COPD. 2010;7(6):428-437.

8. O'Donnell DE, Laveneziana P. Dyspnea and activity limitation in COPD: mechanical factors. COPD. 2007;4(3):225-236.

9. O'Donnell DE, Revill SM, Webb KA. Dynamic hyperinflation and exercise intolerance in chronic obstructive pulmonary disease. Am J Respir Crit Care Med. 2001;164(5):770-777.

10. Oh YM, Sheen SS, Park JH, et al. Emphysematous phenotype is an independent predictor for frequent exacerbation of COPD. Int J Tuberc Lung Dis. 2014;18(12):1407-1414.

11. Casanova C, Cote C, de Torres JP, et al. Inspiratory-to-total lung capacity ratio predicts mortality in patients with chronic obstructive pulmonary disease. Am J Respir Crit Care Med. 2005;171(6):591-597.

12. Tantucci $\mathrm{C}$, Donati $\mathrm{P}$, Nicosia $\mathrm{F}$, et al. Inspiratory capacity predicts mortality in patients with chronic obstructive pulmonary disease. Respir Med. 2008;102(4):613-619.

13. Miller MR, Hankinson J, Brusasco V, et al. Standardisation of spirometry. Eur Respir J. 2005;26(2):319-338.

14. Wanger J, Clausen JL, Coates A, et al. Standardisation of the measurement of lung volumes. Eur Respir J. 2005;26(3):511-522.

15. Pellegrino R, Viegi G, Brusasco V, et al. Interpretative strategies for lung function tests. Eur Respir J. 2005;26(5):948-968.

16. Stocks J, Quanjer PH. Reference values for residual volume, functional residual capacity and total lung capacity. Eur Respir J. 1995;8(3): 492-506.

17. Zheng J, Zhong N. Normative values of pulmonary function testing in Chinese adults. Chin Med J (Engl). 2002;115(1):50-54.

18. Zhang FQ, Zheng JP, Wang JH, et al. [Comparison of lung volume response with airflow response to bronchodilator in patients with chronic obstructive pulmonary disease]. Zhonghua Jie He He Hu Xi Za Zhi. 2010;33(2):109-113.

19. Jian W, Zheng J, Hu Y, Li Y, Gao Y, An J. What is the difference between $\mathrm{FEV}_{1}$ change in percentage predicted value and change over baseline in the assessment of bronchodilator responsiveness in patients with COPD? J Thorac Dis. 2013;5(4):393-399.

20. Ortega F, Márquez-Martín E, Valencia B, et al. Impact of bronchodilator responsiveness on quality of life and exercise capacity in patients with COPD. Respir Care. 2014;59(1):81-89.

21. Alves GR, Marchiori E, Irion KL, et al. The effects of dynamic hyperinflation on CT emphysema measurements in patients with COPD. Eur J Radiol. 2014;83(12):2255-2259.

22. Stoel BC, Putter H, Bakker ME, et al. Volume correction in computed tomography densitometry for follow-up studies on pulmonary emphysema. Proc Am Thorac Soc. 2008;5(9):919-924.

23. Sun XW, Gu SY, Li QY, et al. Pulmonary function parameters in highresolution computed tomography phenotypes of chronic obstructive pulmonary disease. Am J Med Sci. 2015;349(3):228-233.

24. Albert P, Agusti A, Edwards L, et al. Bronchodilator responsiveness as a phenotypic characteristic of established chronic obstructive pulmonary disease. Thorax. 2012;67(8):701-708.

25. Zhong N, Wang C, Yao W, et al. Prevalence of chronic obstructive pulmonary disease in China: a large, population-based survey. Am J Respir Crit Care Med. 2007;176(8):753-760.

\section{Dovepress}

This journal is indexed on PubMed Central, MedLine and CAS. The manuscript management system is completely online and includes a very quick and fair peer-review system, which is all easy to use. Visit $\mathrm{http} / / / \mathrm{www}$.dovepress.com/testimonials.php to read real quotes from published authors. 